\title{
Religious/spiritual coping and level of hope in patients with cancer in chemotherapy
}

\author{
Coping religioso/espiritual e nível de esperança em pacientes com câncer em quimioterapia \\ Coping religioso/espiritual y nivel de esperanza en pacientes con cáncer en quimioterapia
}

Diogo Timóteo Costa'

Darine Marie Rodrigues da Silva" ORCID: 0000-0001-9111-6380

lago Dillion Lima Cavalcanti' ORCID: 0000-0001-6625-8395

Eduardo Tavares Gomes' ORCID: 0000-0002-9506-5303

Juliana Lúcia de Albuquerque Vasconcelos"II ORCID: 0000-0001-7429-1398

Maria Valéria Gorayeb de Carvalho"' ORCID: 0000-0001-5493-3234

'Universidade Federal de Pernambuco. Recife, Pernambuco, Brasil.

"Universidade de Pernambuco. Recife, Pernambuco, Brasil.

I" Centro Universitário Tabosa de Almeida. Caruaru, Pernambuco, Brasil.

How to cite this article: Costa DT, Silva DMR, Cavalcanti IDL, Gomes ET, Vasconcelos JLA, Carvalho MVG. Religious/spiritual coping and level of hope in patients with cancer in chemotherapy. Rev Bras Enferm. 2019;72(3):640-5. doi: http://dx.doi.org/10.1590/0034-7167-2018-0358

Corresponding Author: Diogo Timóteo Costa E-mail:diogotcosta2@gmail.com

Submission: 07-16-2018 Approval: 02-16-2019

\section{ABSTRACT}

Aim: To demonstrate the relationship between religious/spiritual coping and hope in cancer patients undergoing chemotherapy. Method: This is a cross-sectional, descriptive study with a quantitative approach performed in a reference outpatient clinic in Caruaru, PE, between August and October 2017. A total of 82 cancer patients undergoing chemotherapy were included in the study, using the brief religious/ spiritual coping scale (RCOPE-Brief) and the Herth Hope Scale (HHS). Results: The sample presented mean positive RCOPE scores $(3.03 \pm 0.41)$ and the level of hope was considered high (42.7 points \pm 3.67 ). Patients who had a high RCOPE score were found to have a higher mean of Herth's level of hope (44.12 points). Conclusion: This study becomes relevant to nursing professionals by encouraging care that takes into account the patient's spiritual dimension in order to stimulate positive mechanisms of religious coping and, consequently, raise the levels of hope.

Descriptors: Spirituality; Neoplasms; Psychological adaptation; Hope; Nursing

\section{RESUMO}

Objetivo: demonstrar a relação entre o coping religioso/espiritual e a esperança em pacientes com câncer em tratamento quimioterápico. Método: trata-se de um estudo transversal, descritivo, com abordagem quantitativa, realizado em um ambulatório de referência em tratamento quimioterápico de Caruaru-PE, entre agosto e outubro de 2017. Participaram da pesquisa 82 pessoas com câncer em tratamento quimioterápico, utilizando-se a escala de coping religioso/espiritual breve (CRE-Breve) e a escala de esperança de Herth (EEH). Resultados: a amostra apresentou escores médios de CRE positivo $(3,03 \pm 0,41)$, e o nível de esperança foi considerado alto ( 42,7 pontos; $\pm 3,67$ ). Verificou-se que os pacientes que tiveram classificação alta do CRET apresentaram maior média do nível de esperança de Herth (44,12 pontos). Conclusão: este estudo torna-se relevante aos profissionais de enfermagem ao encorajar cuidados que contemplem a dimensão espiritual do paciente a fim de estimular os mecanismos positivos do CRE e, consequentemente, elevar os níveis de esperança.

Descritores: Espiritualidade; Neoplasias; Adaptação Psicológica; Esperança; Enfermagem.

\section{RESUMEN}

Objetivo: demostrar la relación entre el coping religioso/espiritual y la esperanza en pacientes con cáncer en tratamiento quimioterápico. Método: se trata de un estudio transversal, descriptivo, con abordaje cuantitativo, realizado en un ambulatorio de referencia en tratamiento quimioterápico de Caruaru-PE, entre agosto y octubre de 2017. Participaron de la investigación 82 personas con cáncer en tratamiento quimioterápico, escala de coping religioso/espiritual breve (CRE-Breve) y la escala de esperanza de Herth (EEH). Resultado: la muestra presentó escores medios de CRE positivo $(3,03 \pm 0,41)$ y el nivel de esperanza fue considerado alto $(42,7$ puntos, $\pm 3,67)$. Se verificó que los pacientes que tuvieron clasificación alta del CRET presentaron mayor promedio del nivel de esperanza de Herth (44,12 puntos). Conclusión: se vuelve relevante a los profesionales de enfermería para alentar los cuidados que contemplan la dimensión espiritual del paciente a fin de estimular los mecanismos positivos del CRE $y$, consecuentemente, elevar los niveles de esperanza.

Descriptores: Espiritualidad; Neoplasias; Adaptación Psicológica; Esperanza; Enfermería. 


\section{INTRODUCTION}

In Brazil, cancer is considered a public health problem whose incidence is on the rise. According to estimates by the National Cancer Institute (Inca), about 600 thousand new cases of cancer were predicted for the $2016 / 2017$ biennium. In this estimation we also found the most frequent types of cancer, which are those of prostate and lung in the male sex, and of the breast, colon and rectum in the female sex ${ }^{(1)}$.

Despite technological advances in the health sciences, which have allowed new forms of treatment for diseases considered true fatalities in the past, cancer continues to be generally perceived as an incurable disease. Due to the social "weight" of the disease, combined with incurability and changes in lifestyle, the diagnosis of an oncologic disease triggers negative emotions related to pain and suffering, and it also brings out in the individual the idea that life is limited ${ }^{(2-3)}$.

By raising the idea of proximity to death, cancer reaches the human being in its biopsychosocial and spiritual totality, as it also generates inquiries of existential nature and situations that cause feelings of hopelessness. In seeking a new meaning for this lifethreatening reality, religiosity and spirituality can have beneficial effects on the individual, such as reduction of disturbing experiences due to cancer and improvement of the quality of life $\mathrm{e}^{(2,4)}$.

Spirituality has been the subject of research regarding its role as a coping strategy used by cancer patients, considering its importance, as well as that of religion, by exerting a protective effect against the negative impacts resulting from oncologic disease. In this regard, spirituality is expressed by each individual in a peculiar way, inherent in its intrinsic nature, which makes it possible to renew the hope of surviving cancer, since religious and spiritual beliefs provide possibilities for re-signifying life experiences, especially in relation to the process of falling $\mathrm{ill}^{(5)}$.

In this sense, coping refers to a set of behavioral and cognitive strategies used to deal with stress situations. When the individual makes use of religion, spirituality or faith as a coping strategy to deal with contexts that can cause physical, mental and spiritual exhaustion, there is religious/spiritual coping (RCOPE) $)^{(5)}$.

With regard to hope, it is an essential feeling for coping with cancer, and can be considered one of the most important aspects for nursing care. This is because it contributes to acceptance of the new condition of the disease, allowing a greater capacity to cope with crisis situations, as well as the maintenance of good behaviors related to long periods of treatment ${ }^{(6)}$.

It is important to consider that during chemotherapy, in addition to the thoughts that the patient evokes when associating the diagnosis of cancer with the impossibility of cure, such form of treatment can further aggravate feelings of fear, anxiety and hopelessness due to drug reactions that cause suppression of the immune system. Thus the need for the presence of nurses committed to identify these moments of physical, social and spiritual fragility ${ }^{(7)}$.

Being aware of the religious and spiritual aspects of an individual means understanding his/her deepest perceptions, related to his/her way of being and existing in the world, allowing the health professional a broader understanding of his/her needs ${ }^{(8)}$. It is relevant for the nurse to understand the values of religious and spiritual beliefs as well as the level of hope of patients during the treatment of cancer, in order to promote an individualized assistance to the patient during the chemotherapeutic treatment.

\section{AIM}

To demonstrate the relationship between religious/spiritual coping and hope in cancer patients on chemotherapy.

\section{METHOD}

\section{Ethical aspects}

This study respected the ethical precepts of Resolution 466/2012 of the National Health Council, and the research was approved by the Research Ethics Committee of the Centro Universitário Tabosa de Almeida (Asces/Unita).

\section{Design, place and period of study}

This is a cross-sectional, descriptive study with a quantitative approach, carried out in a reference outpatient clinic in Caruaru, PE between August and October 2017. The outpatient clinic is a reference for patients requiring chemotherapy treatment and receives patients from all over the state of Pernambuco (PE).

\section{Population and sample}

The calculation of the minimum sample required to obtain statistically significant results was done using software Sample Size Calculator by Raosoft. For this calculation, a population of 1,200 patients registered for treatment at the study site was taken into account. A maximum error of $5 \%$ and a design effect of 1 were considered. Thus, a minimum number of 292 patients enrolled using antineoplastic chemotherapy was established so that the results obtained had a confidence level of $95 \%$.

\section{Inclusion and exclusion criteria}

People of both sexes, aged over 18 years, diagnosed with cancer and undergoing curative and/or palliative chemotherapy participated in the study. Patients who were in the post-treatment phase, who were undergoing radiotherapy treatment concomitant with chemotherapy, who had recurrence of cancer or those who were unaware of the purpose of the treatment were not included in the study.

\section{Study protocol}

Patients were approached during chemotherapy sessions. After being explained the purpose of the study, patients were asked to sign a free and informed consent form to participate in the research. An interview was conducted so that participants could answer the questionnaire, since, in most cases, the upper limb was punctured for infusion of the medication. During the interview there was no interpretation of the questions by the interviewer, nor interference of the companions.

For data collection we used the Brief Spiritual/Religious Coping Scale (CRE-Brief), the Herth Hope Scale (HHS) and the 
questionnaire adapted by the researcher were used $(5,9,10)$. This questionnaire was divided into two parts: Part $A$, with the purpose of characterizing sociodemographic data; and part $B$, in order to indicate clinical aspects related to the patient's tumor.

The CRE-Brief scale, validated by Panzini and Bandeira ${ }^{(11)}$, allows to evaluate the use of spirituality/religiosity by the individual as a coping mechanism when affected by the disease. The answers are given in a five-point Likert scale, ranging from 1 (not at all) to 5 (very much). The scale contains 49 items, divided into three dimensions ${ }^{(5)}$ :

- Positive CRE (PCRE): corresponds to the level of positive religious/spiritual coping practiced by the individual, indicated by 34 items in the scale;

- Negative CRE (NCRE): corresponds to the level of negative religious/spiritual coping practiced by the individual, indicated by 15 scale items;

- Total CRE (TCRE): corresponds to the total amount of CRE practiced by the individual, indicated by the average of PCRE responses and the average of inverted NCRE responses.

The parameters used to analyze the mean values of the CRE-Brief were: none or negligible (1.00 to 1.50); low (1.51 to 2.50); medium (2.51 to 3.50); high (3.51 to 4.50); and very high (4.51 to 5.00$)^{(5)}$.

To assess the level of hope, the Herth Hope Scale (HHS) validated by Sartore and Grossi ${ }^{(12)}$ was used. HHS is a self-report scale that quantifies hope in life. It comprises 12 items, written affirmatively, in which the items are graded by a Likert-like scale from 1 to 4 points, where point 1 indicates "strongly disagree" and 4 indicates "strongly agree". The total score ranges from 12 to 48, and the higher the score, the higher the level of hope in life ${ }^{(10)}$.

\section{Analysis of results and statistics}

The data processing was built in a bank in the Epi Info program, version 3.5.4, which was exported to the Statistical Package for the Social Sciences (SPSS), version 18, through which the analysis was performed. To evaluate participants' personal, housing, financial, religious and clinical profile, relative frequencies were calculated and the respective frequency distributions were constructed. To compare the percentages found in the levels of the factors evaluated, the chi-square test was used to compare proportion. In the evaluation of quantitative variables, the following statistics were calculated: minimum, maximum, mean and standard deviation. In order to determine the factors associated with religious/spiritual coping and hope of participants, Student's t-test and analysis of variance (ANOVA) were applied, since the normality of CRE and HHS scores was indicated by the Kolmogorov-Smirnov test. All conclusions were drawn considering the significance level of $5 \%$.

\section{RESULTS}

Of the 292 patients selected, 210 were excluded because they did not meet the inclusion criteria, 145 of whom used other nonchemotherapeutic drugs, such as bisphosphonates, hormones and immunotherapeutics, and 65 underwent chemotherapy combined with radiotherapy. Thus, 82 interviewees were included, observing that there was a predominance of female patients (68)
(82.9\%). Regarding skin color, 60 (73.3\%) were non-whites, and 37 (45.1\%) had a predominant age between 41 and 59 years. Regarding schooling, 48 (58.8\%) completed elementary school or less. Regarding marital status, 44 (53.7\%) had a partner, 70 (85.4\%) had children, and 73 (89\%) were from urban areas. Regarding the financial profile, $68(82.9 \%)$ had income of two minimum wages or more, and 68 (53.8\%) were retirees, pensioners or no activity.

Regarding the religious profile, 75 (91.5\%) had a religion and, of these, 56 (68.3\%) declared themselves Catholic. Regarding the clinical profile, 50 (61\%) had breast cancer, 47 (57.3\%) were diagnosed within one year, 69 (86.3\%) underwent adjuvant or palliative chemotherapy, and 23 (29\%) had stage IV cancer. In addition, 51 (62.2\%) underwent chemotherapy for up to one year, and 40 (49.4\%) underwent up to six sessions.

The majority of patients had medium TCRE $(57 ; 69.5 \%)$, followed by the group with high TCRE $(25 ; 30.5 \%)$. The proportion comparison test was significant ( $p$-value $<0.001$ ), indicating that the number of patients with medium CRE is significantly higher (Table 1).

Table 1 - Results of distribution of the brief religious/spiritual coping scale according to domains and total evaluation. Caruaru, PE, Brazil, 2017

\begin{tabular}{lcccc}
\hline \multirow{2}{*}{ CRE classification } & \multicolumn{2}{c}{ CRE Domains } & Total CRE & \multirow{2}{*}{ p value } \\
& Positive & Negative & & \\
\hline None or negligible & $0(0.0 \%)$ & $24(29.3 \%)$ & $0(0.0 \%)$ & \\
Low & $7(8.5 \%)$ & $51(62.2 \%)$ & $0(0.0 \%)$ & \\
Medium & $68(82.9 \%)$ & $7(8.5 \%)$ & $57(69.5 \%)$ & \multirow{2}{*}{001} \\
High & $7(8.5 \%)$ & $0(0.0 \%)$ & $25(30.5 \%)$ & $<0.001$ \\
Very High & $0(0.0 \%)$ & $0(0.0 \%)$ & $0(0.0 \%)$ & \\
Minimum-maximum & $2.06-4.12$ & $1.00-3.20$ & $2.73-4.31$ & - \\
Mean \pm standard deviation & $3.03 \pm 0.41$ & $1.79 \pm 0.49$ & $3.39 \pm 0.27$ & - \\
\hline Note: CRE: religious/spiritual coping; ${ }^{1} p$-value of chi-square test. & & \\
\hline
\end{tabular}

Among the items assessed by HHS, Table 2 shows that item number 2 had the lowest mean score of $3.15( \pm 0.80)$, demonstrating that $20.7 \%$ of the sample disagreed $=15$ ) or strongly disagreed $(n=2)$ with the statement "I have short and/or long range goals.". On the other hand, the item with the highest mean score was number 12, "I feel my life has value and worth", with a mean of 3.88 $( \pm 0.33)$. As a result, $100.0 \%$ of the respondents agreed $(n=10)$ or strongly agreed $(n=72)$ with that statement. The patients' level of hope presented a mean score of 42.7 points $( \pm 3.67)$ and median of 43 points, with scores between 34 and 48 .

Table 3 shows the relationship between TCRE and the level of hope through HHS. The group with a high TCRE classification had a higher mean HHS (mean = 44.12 points), followed by the group with medium TCRE (mean $=42.07$ points). Moreover, the distribution comparison test was significant ( $p$-value $=0.019$ ), indicating that the distribution of HHS grade differs across TCRE classifications.

Table 4 presents the Pearson correlation coefficient between CRE and HHS domains. PCRE and TCRE have a directly proportional correlation with the Herth score, that is, an increase of PCRE and TCRE imply an increase of HHS. For NCRE, a weak inversely proportional correlation with total Herth score was found, indicating that an increase of NCRE leads to a non-relevant reduction in the patient's level of hope. Although these relationships were found, the correlation test was significant only for the TCRE score ( $p$-value = 0.253 ), indicating that CRE significantly changes the level of hope. 
Table 2 - Descriptive statistics of hope in cancer patients on chemotherapy. Caruaru, PE, Brazil, 2017

\begin{tabular}{lcccc}
\hline Variables & Mean & $\begin{array}{c}\text { Standard } \\
\text { deviation }\end{array}$ & Median & $\begin{array}{c}\text { Variation } \\
\text { obtained }\end{array}$ \\
\hline 1. I have a positive outlook toward life. & 3.51 & 0.72 & 4 & $1-4$ \\
2. I have short and/or long range goals. & 3.15 & 0.80 & 3 & $1-4$ \\
3. I feel all alone. & 3.41 & 0.86 & 4 & $1-4$ \\
4. I can see possibilities in the midst of difficulties. & 3.38 & 0.64 & 3 & $1-4$ \\
5. I have a faith that gives me comfort. & 3.82 & 0.50 & 4 & $1-4$ \\
6. I feel scared about my future. 7. & 3.46 & 0.80 & 4 & $1-4$ \\
7. I can recall happy/joyful times. & 3.56 & 0.63 & 4 & $1-4$ \\
8. I have deep inner strength. & 3.70 & 0.56 & 4 & $2-4$ \\
9. I am able to give and receive caring/love. & 3.70 & 0.49 & 4 & $2-4$ \\
10. I have a sense of direction. & 3.40 & 0.74 & 4 & $2-4$ \\
11. I believe that each day has potential. & 3.73 & 0.47 & 4 & $2-4$ \\
12. I feel my life has value and worth. & 3.88 & 0.33 & 4 & $3-4$ \\
\hline
\end{tabular}

Table 3 - Evaluation of the relationship between the brief religious/spiritual coping scale and the level of hope of the Herth scale. Caruaru, PE, Brazil, 2017

\begin{tabular}{lccc}
\hline Variables & \multicolumn{2}{c}{ TCRE Classification } & \\
& CRET médio & CRET alto & \\
\hline 1. I have a positive outlook toward life. & $3.46 \pm 0.80$ & $3.64 \pm 0.49$ & $0.530^{2}$ \\
2. I have short and/or long range goals. & $3.04 \pm 0.84$ & $3.40 \pm 0.64$ & $0.073^{2}$ \\
3. I feel all alone. & $3.30 \pm 0.94$ & $3.68 \pm 0.56$ & $0.127^{2}$ \\
4. I can see possibilities in the midst of difficulties. & $3.26 \pm 0.64$ & $3.64 \pm 0.57$ & $\mathbf{0 . 0 0 9 ^ { 2 }}$ \\
5. I have a faith that gives me comfort. & $3.84 \pm 0.41$ & $3.76 \pm 0.66$ & $0.786^{2}$ \\
6. I feel scared about my future. 7. & $3.40 \pm 0.88$ & $3.60 \pm 0.58$ & $0.537^{2}$ \\
7. I can recall happy/joyful times. & $3.53 \pm 0.66$ & $3.64 \pm 0.57$ & $0.474^{2}$ \\
8. I have deep inner strength. & $3.61 \pm 0.59$ & $3.88 \pm 0.44$ & $\mathbf{0 . 0 2 1 ^ { 2 }}$ \\
9. I am able to give and receive caring/love. & $3.67 \pm 0.51$ & $3.76 \pm 0.44$ & $0.467^{2}$ \\
10. I have a sense of direction. & $3.35 \pm 0.77$ & $3.52 \pm 0.65$ & $0.396^{2}$ \\
11. I believe that each day has potential. & $3.75 \pm 0.47$ & $3.68 \pm 0.48$ & $0.414^{2}$ \\
12. I feel my life has value and worth. & $3.86 \pm 0.35$ & $3.92 \pm 0.28$ & $0.445^{2}$ \\
Total Herth Scale Score & $42.07 \pm 3.65$ & $44.12 \pm 3.37$ & $\mathbf{0 . 0 1 9 ^ { 1 }}$ \\
& & &
\end{tabular}

Note: TCRE: total religious/spiritual coping; ' $p$-value of Student's $t$-test. ${ }^{2} p$-value of Mann-Whitney test.

Table 4 - Association between religious-spiritual coping and hope of cancer patients on chemotherapy. Caruaru, PE, Brazil, 2017

\begin{tabular}{lc}
\hline Rated domain & p value' $^{1}$ \\
\hline Positive CRE & 0.213 \\
Negative CRE & -0.055 \\
Total CRE & 0.253 \\
\hline
\end{tabular}

Note: CRE: religious/spiritual coping; ' $p$-value of Pearson correlation test.

\section{DISCUSSION}

Because cancer is a life-threatening chronic disease, the cancer patient often finds himself faced with "death" and this brings questions about the meaning of life, anguish, fear, and suffering, leading to a significant increase in spiritual needs and possibly an existential crisis. A cancer patient will experience the worst symptoms not only because of the damage caused by the disease, but also because of the toxicity of antineoplastic agents, which cause poor quality of life, as well as emotional, social and spiritual suffering ${ }^{(13-14)}$.

Therefore, providing care that takes into account the individual's spirituality is a way of encompassing spiritual needs and promoting quality of life. Such needs are the driving force for the search for meaning in life and impel to overcome suffering and difficulties, especially for those who have cancer and are undergoing treatment ${ }^{(15-16)}$.

A study ${ }^{(17)}$ designed to investigate the relationship between coping strategies, quality of life and mood in patients with incurable cancer identified that patients used several coping strategies early in treatment. In our study, all patients undergoing chemotherapy treatment used religious coping (CRE) to manage their health status.

It was observed that many of the patients in the study seek religion/spirituality as a way of coping with neoplastic disease. However, the way in which the individual makes use of religious coping may bring benefits, such as lower incidence of diseases or complications during treatment and greater longevity, or may lead to greater anxiety and depression and lower levels of hope and spiritual well-being ${ }^{(15)}$. In this study, the predominance of patients presenting with PCRE in the medium rating may indicate that there was no relevant negative emotional impact caused by cancer, due to behaviors that define coping strategies as positive, such as praying for the well-being of others and seeking protection, support, love and guidance in God $^{(18-19)}$.

The way the individual emanates his spirituality is directly related to his coping strategies, and faith in God is expressed in complex and unfavorable situations. In this case, religiosity and spirituality, through faith, allow the patient to adjust to cancer and derive positive thoughts from stressful experiences in order to bring about a change of life ${ }^{(20)}$. Coupled with religious and spiritual beliefs, high levels of hope provide satisfaction and well-being, raising resilience to life-threatening diseases ${ }^{(21)}$.

The results obtained through $\mathrm{HHS}$ (total score of 42.7) were elevated, similarly to a study of 96 patients on chemotherapy, where it reached $40.80( \pm 4.45)$ (22). In a cross-sectional cohort study that sought to identify the level of hope in 60 cancer patients at the beginning and at the end of treatment, 35.8 ( \pm 6.11 ) at the first moment and $36.1( \pm 7.12)$ at the second moment ${ }^{(23)}$ were the scores obtained. Another study reported a total score of $38.06( \pm 4.32)$ in 127 renal patients on hemodialysis ${ }^{(10)}$.

Regarding HHS items that reached excellent scores, the statement "I have a faith that gives me comfort" indicated that patients have faith as a valuable spiritual component for maintaining well-being, helping in a satisfactory outlook for coping and providing satisfaction of life. In addition, this indicates the possibility of relating to God and transcendental forces through prayers to reinforce the perspective of health improvement and quality of life in the future, which also means tolerating stressful characteristics experienced in the present moment, throughout treatment ${ }^{(21)}$.

The findings of this study are similar to the reality reported in another study, in which the item "I feel my life has value and 
worth" presented higher scores ${ }^{(23)}$. It is emphasized that patients, despite having a disease in which there is a strong tendency to weaken physical, social, mental and spiritual aspects, recognize that life is a greater good, superior to any adverse circumstance that both cancer and, possibly, treatment impose. As a consequence of the awareness of this value inherent in human existence, selfrecognition comes through the feeling of usefulness, allowing the sharing of values, actions and feelings with others.

However, these authors identified that the item with the lowest score (mean of 2.67 and \pm 1.05 ) was the statement "I feel all alone", in contrast to this study, where the statement "I have short and/or long range goals" was the one with the lowest score (mean of 3.15 and \pm 0.80 ). Thus, it is important to reflect on the work of professionals involved in the care of patients undergoing chemotherapy treatment, seeking to implement subjective character actions, such as active listening, to gather complaints and understand the feelings that might compromise hope levels ${ }^{(23)}$.

The positive association between the highest hope score and the high TCRE indicates that it is relevant to deliver care related to the individual's spiritual dimension, since the results of a study ${ }^{(5)}$ indicate that patients on chemotherapy consider religion/ spirituality an important tool for coping with the disease, but few were approached in this regard.

Therefore, to carry out interventions of a spiritual nature taking into account the patient's CRE can show the care provider the coping strategies used by the subject and instigate him to reflect on possible deleterious perspectives that are negatively affecting his health, since, during the nursing care, the being is perceived in its biopsychosocial and spiritual dimensions. Consequently, seeking positive aspects of these strategies will reverberate in raising and maintaining hope throughout treatment, given that the prevalence of hopelessness in cancer patients is related to spiritual distress and lower levels of spiritual well-being ${ }^{(13-14)}$.

\section{Limitations of the study}

This study had limitations during data collection, since some patients residing in municipalities outside the study site were somewhat apprehensive while answering questionnaires for fear of missing the transportation offered by the local government to return to their homes. Also, the room in which the interviews were conducted was small and could not admit many patients, which made it difficult to interview a larger number of people. Many of the patients were illiterate and asked the interviewer to explain some questions they could not understand. As the data collection site did not have a computer system capable of identifying the exact number of patients undergoing chemotherapy, it was difficult to perform the population calculation for the study, which was performed according to the total number of patients attended at the outpatient clinic, thus resulting in a high study population, drastically reduced due to the exclusion criteria proposed.

\section{Contributions to the area of nursing, health or public population}

Taking into consideration the presented context, this study points out the relevance of nurses considering the spiritual dimension as a fundamental component in the care process of patients undergoing chemotherapy. In this sense, care will be a driving force to positively enhance the religious/spiritual coping mechanisms that these patients manage before, during and after each chemotherapy session, as well as to develop a hope-oriented attitude in the patient and family.

Given this scenario, the nurse is reinforced as a protagonist of the care process by establishing a link in the nurse-patientfamily relationship that will permeate humanistic values and metaphysical ideals, so as to enhance an integral view of this triad. Through the inclusion of spirituality, the act of caring will embrace the objective and subjective dimension of the patient and family that experience chemotherapy treatment.

\section{CONCLUSION}

This study evidences that most of the patients presented PCRE in medium level as a coping strategy. In addition, they presented high levels of hope during the chemotherapy treatment as compared to other studies. Regarding the statements contained in the HHS, most patients value themselves and feel useful for society, even though they are periodically submitted to chemotherapy. Nevertheless, it has been shown that individuals who use positive coping strategies present high levels of hope.

This study is relevant for nursing professionals because, as they are in direct contact with patients and their families throughout chemotherapy, they have the opportunity to establish a relationship in which it becomes possible to detect the religious and spiritual needs of the patient-family binomial. Therefore, spiritualityoriented care will be directed toward the individual, respecting his/her worldview, which will bring benefits by positively using his/her coping strategies, maintaining and raising his/her hope.

Thus, further studies should be conducted that seek to demonstrate the relationship between levels of hope and religious/ spiritual coping in cancer patients, at different times throughout the treatment, to identify possible factors influencing these levels and, consequently, to promote health in a holistic perspective.

\section{REFERENCES}

1. Ministério da Saúde (BR), Instituto Nacional de Câncer José Alencar Gomes da Silva (INCA). Estimativa 2016: incidência de câncer no Brasil. Rio de Janeiro: Inca; 2015 [cited 2019 Jan 30]. 122 p. Available from: http://santacasadermatoazulay.com.br/wp-content/uploads/2017/06/ estimativa-2016-v11.pdf

2. Farinhas GV, Wendling MI, Dellazzana-zanon LL. [Psychological impact of a cancer diagnosis on the family: a case study on the perception of the caregiver]. Pensando Fam [Internet]. 2013 [cited 2019 Jan 30];17(2):111-29. Available from: http://pepsic.bvsalud.org/scielo. php?script=sci_arttext\&pid=S1679-494X2013000200009 Portuguese. 
3. Guerrero GP, Zago MMF, Sawada NO, Pinto MH. [Relationship between spirituality and cancer: patient's perspective]. Rev Bras Enferm [Internet]. 2011 [cited 2019 Mar 15];64(1):53-9. Available from: http://dx.doi.org/10.1590/S0034-71672011000100008 Portuguese.

4. Gobatto CA, Araujo TCCF. [Religiosity and spirituality in oncology: Health Professionals' conceptions]. Psicol USP [Internet]. 2013 [cited 2019 Mar 15];24(1):11-34. Available from: http://dx.doi.org/10.1590/S0103-65642013000100002 Portuguese.

5. Mesquita AC, Chaves ECL, Avelino CCV, Nogueira DA, Panzini RG, Carvalho EC. The use of religious/spiritual coping among patients with cancer undergoing chemotherapy treatment. Rev Lat Am Enfermagem [Internet]. 2013 [cited 2019 Mar 15];21(2):539-45. Available from: http://dx.doi.org/10.1590/S0104-11692013000200010

6. Orlandi FS, Praça NS. The hope of women with HIV/AIDS: evaluation using the herth scale. Texto Contexto Enferm [Internet]. 2013 [cited 2019 Mar 15];22(1):141-8. Available from: http://dx.doi.org/10.1590/S0104-07072013000100017

7. Lopes RFF, Santos MR, Lopes EJ. Efeitos do relaxamento sobre a ansiedade e desesperança em mulheres com câncer. Rev Bras Ter Comp Cogn [Internet]. 2008 [cited 2019 Jan 30];10(1):39-49. Available from: https://doi.org/10.31505/rbtcc.v10i1.179

8. Bousso RS, Poles K, Serafim TS, Miranda MG. Religious beliefs, illness and death: family's perspectives in illness experience. Rev Esc Enferm USP [Internet]. 2011 [cited 2019 Mar 15];45(2):391-7. Available from: http://dx.doi.org/10.1590/S0080-62342011000200014

9. Corrêa CSL, Leite IC, Andrade AP, Souza SFA, Carvalho SM, Guerra MR. Sexual function of women surviving cervical cancer. Arch Gynecol Obstet [Internet]. 2016 [cited 2019 Mar 15];293(5):1053-63. Available from: https://doi.org/10.1007/s00404-015-3857-0

10. Ottaviani AC, Souza EM, Drago NC, Mendiondo MSZ, Pavarini SCL, Orlandi FS. Hope and spirituality among patients with chronic kidney disease undergoing hemodialysis: a correlational study. Rev Lat Am Enfermagem [Internet]. 2014 [cited 2019 Mar 15];22(2):248-54. Available from: http://dx.doi.org/10.1590/0104-1169.3323.2409

11. Panzini RG, Bandeira DR. [Spiritual/religious coping scale (SRCOPE Scale): elaboration and construct validation]. Psicol Estud [Internet]. 2005 [cited 2019 Jan 30];10(3):507-16. Available from: http://dx.doi.org/10.1590/S1413-73722005000300019 Portuguese.

12. Sartore AC, Grossi SAA. [Herth Hope index - instrument adapted and validated to Portuguese]. Rev Esc Enferm USP [Internet]. 2008 [cited 2019 Mar 15];42(2):227-32. Available from: http://dx.doi.org/10.1590/S0080-62342008000200003 Portuguese.

13. Sajadi M, Niazi N, Khosravi S, Yaghobi A, Rezaei M, Koenig HG. Effect of spiritual counseling on spiritual well-being in Iranian women with cancer: a randomized clinical trial. Complement Ther Clin Pract [Internet]. 2018 [cited 2019 Mar 15];30:79-84. Available from: https://doi. org/10.1016/j.ctcp.2017.12.011

14. Sankhe A, Dalal K, Agarwal V, Sarve P. Spiritual care therapy on quality of life in cancer patients and their caregivers: a prospective nonrandomized single-cohort study. J Relig Health [Internet]. 2017 [cited 2019 Mar 15];56(2):725-31. Available from: https://dx.doi.org/10.1007 \%2Fs10943-016-0324-6

15. Sousa FFPRD, Freitas SMFM, Farias AGS, Cunha MCSO, Araujo MFM, Veras VS. Religious/spiritual coping by people with cancer undergoing chemotherapy: integrative literature review. Rev Eletrônica Saúde Mental Álcool Drog [Internet]. 2017 [cited 2019 Mar 15];13(1):45-51. Available from: http://dx.doi.org/10.11606/issn.1806-6976.v13i1p45-51

16. Pinto S, Caldeira S, Martins JC. [Spirituality of cancer patients under chemotherapy]. CuidArte Enfermagem [Internet]. 2012 [cited 2019 Jan 30];6(1):8-14. Available from: http://fundacaopadrealbino.org.br/facfipa/ner/pdf/CuidArte\%20Enfermagem\%20v\%206\%20n\%201\%20 jan.\%20jun.\%202012.pdf Portuguese.

17. Nipp RD, El-Jawahri A, Fishbein JN, Eusebio J, Staql JM, Gallagher ER, et al. The relationship between coping strategies, quality of life, and mood in patients with incurable cancer. Cancer [Internet]. 2016 [cited 2019 Mar 15];122(13):2110-6. Available from: https://dx.doi. org/10.1002\%2Fcncr.30025

18. Matos TDS, Meneguin S, Ferreira MLS, Miot HA. Quality of life and religious-spiritual coping in palliative cancer care patients. Rev Lat Am Enfermagem [Internet]. 2017 [cited 2019 Mar 15];25:e2910. Available from: http://dx.doi.org/10.1590/1518-8345.1857.2910

19. Valcanti CC, Chaves ECL, Mesquita AC, Nogueira DA, Carvalho EC. Religious/spiritual coping in people with chronic kidney disease undergoing hemodialysis. Rev Esc Enferm USP [Internet]. 2012 [cited 2019 Mar 15];46(4):837-43. Available from: http://dx.doi.org/10.1590/ S0080-62342012000400008

20. Rezaei H, Forouzi MA, Abadi OSRR, Tirgari B. Relationship between religious beliefs and post-traumatic growth in patients with cancer in southeast of Iran. Ment Health Relig Cult [Internet]. 2017 [cited 2019 Mar 15];20(1):89-100. Available from: https://doi.org/10.1080/1367467 6.2017 .1324836

21. Jafari E, Najafi M, Sohrabi F, Dehshiri GR, Soleymani E, Heshmati R. Life satisfaction, spirituality well-being and hope in cancer patients. Procedia Soc Behav Sci [Internet]. 2010 [cited 2019 Mar 15];5:1362-6. Available from: https://doi.org/10.1016/j.sbspro.2010.07.288

22. Schuster JT, Feldens VP, Iser BPM, Ghislandi GM. [Hope and depression in patients with cancer at a hospital in southern brazil]. Rev AMRIGS [Internet]. 2015 [cited 2019 Jan 30];59(2):84-9. Available from: http://www.amrigs.org.br/revista/59-02/03_1455_Revista\%20AMRIGS.pdf Portuguese.

23. Wakiuchi J, Marchi JA, Norvila LS, Marcon SS, Sales CA. Hope of cancer patients undergoing chemotherapy. Acta Paul Enferm [Internet]. 2015 [cited 2019 Mar 15];28(3):202-8. Available from: http://dx.doi.org/10.1590/1982-0194201500035 